\title{
Número ideal de amostras para classificação comercial de cultivares de trigo no Brasil
}

\author{
Ricardo Lima de Castro(1), Eduardo Caierão(1), Márcio Só e Silva(1), Pedro Luiz Scheeren(1), \\ Eliana Maria Guarienti ${ }^{(1)}$ e Martha Zavariz de Miranda ${ }^{(1)}$
}

(1)Embrapa Trigo, Rodovia BR-285, Km 294, Caixa Postal 3081, CEP 99050-970 Passo Fundo, RS, Brasil. E-mail: ricardo.castro@embrapa.br,
eduardo.caierao@embrapa.br, marcio.soesilva@embrapa.br, pedro.scheeren@embrapa.br, eliana.guarienti@embrapa.br, martha.miranda@embrapa.br

\begin{abstract}
Resumo - O objetivo deste trabalho foi estimar o número ideal de amostras, para a classificação comercial de cultivares de trigo (Triticum aestivum) quanto à média de força de glúten, no Rio Grande do Sul e no Paraná, principais estados produtores de trigo do Brasil. Resultados de análises de alveografia de amostras de grãos, provenientes de ensaios de competição de três cultivares de trigo (até 280 ensaios, em 11 anos), foram utilizados. O número ideal de amostras foi estimado com base nas propriedades da distribuição amostral da média, por região de adaptação, nos estados do Rio Grande do Sul e do Paraná. O número ideal variou de 13 a 22, 30 a 49, e 121 a 197 amostras por estado, respectivamente, para a margem de erro de 30, 20 e 10 unidades de força de glúten (W), com, no mínimo, 7, 16 e 63 amostras por região de adaptação e por estado, para a margem de erro de 30, 20 e $10 \mathrm{~W}$, respectivamente. O número ideal de amostras para a classificação comercial de cultivares de trigo, no Rio Grande do Sul e no Paraná, é no mínimo de 13 amostras, por estado, e 7 de amostras, por região de adaptação e por estado, para a margem de erro de $30 \mathrm{~W}$, valores que são superiores aos utilizados para a classificação pelos obtentores.
\end{abstract}

Termos para indexação: Triticum aestivum, alveografia, distribuição amostral da média, força de glúten, qualidade tecnológica.

\section{Optimal number of samples for commercial classification of wheat cultivars in Brazil}

\begin{abstract}
The objective of this work was to estimate the optimal number of samples for commercial classification of wheat (Triticum aestivum) cultivars for gluten strength average, in the states of Rio Grande do Sul and Paraná, the main wheat producing regions in Brazil. The alveography analysis results of grain samples, from competition assays of three wheat cultivars (up to 280 experiments in 11 years), were used. The optimal number of samples was estimated based on the properties of the mean sampling distribution by adaptation region, in the states of Rio Grande do Sul and Paraná. The optimal number ranged from 13 to 22,30 to 49, and 121 to 197 samples per state, respectively, for to error margin of 30, 20, and 10 gluten strength units (W), with minimum of 7, 16, and 63 samples per adaptation region and per state for error margin of 30, 20 and $10 \mathrm{~W}$, respectively. The optimal number of samples for commercial classification of wheat cultivars, in the states of Rio Grande do Sul and Paraná, is of at least 13 samples per state and of 7 samples per adaptation region and per state for error margin of $30 \mathrm{~W}$, which are higher values than those used by breeders for classification.
\end{abstract}

Index terms: Triticum aestivum, alveography, sampling distribution of the mean, gluten strength, technological quality.

\section{Introdução}

A qualidade de grãos e farinhas de cereais é determinada por diversas características, que assumem diferentes significados conforme a designação de uso ou tipo de produto (Smanhotto et al., 2006; Módenes et al., 2009). Do volume total de farinha de trigo comercializada no Brasil, aproximadamente 55\% destina-se à panificação, $17 \%$ à fabricação de macarrão, $13 \%$ a biscoitos, $11 \%$ ao uso doméstico e $4 \%$ a outros segmentos (Associação..., 2012).

Para avaliar as características de qualidade e aptidão industrial dos grãos e da farinha de trigo, são empregadas análises físicas, físico-químicas e reológicas (Módenes et al., 2009; Scheuer et al., 2011). Os principais testes reológicos, utilizados na análise 
de qualidade do trigo pelo mercado, são: alveografia, farinografia e mixografia (Gutkoski et al., 2007; Mis et al., 2012). Na alveografia, as principais medidas obtidas são a extensibilidade, a tenacidade e a força do glúten.

O glúten é formado, em aproximadamente 90\%, pelas proteínas gluteninas e gliadinas (Wan et al., 2013), além de $8 \%$ de lipídeos e $2 \%$ de carboidratos (pentosanas solúveis e insolúveis, principalmente). Juntos, as proteínas e os lipídeos do glúten são responsáveis pelas propriedades viscoelásticas e coesivas da massa. A força do glúten (W), expressa em $10^{-4}$ Joules, representa o trabalho (energia) de deformação da massa, que é indicativo da força de panificação da farinha (Módenes et al., 2009). A força de panificação é associada à maior ou à menor capacidade de absorção de água pelas proteínas formadoras do glúten, combinadas à capacidade de retenção do gás carbônico (Olán et al., 2010).

No Brasil, a Instrução Normativa n. ${ }^{\circ}$ 38, de 30 de novembro de 2010, do Ministério da Agricultura, Pecuária e Abastecimento (Brasil, 2010), é usada como referência para classificar as cultivares de trigo de acordo com a força de glúten (obtida por alveografia), a estabilidade (obtida por farinografia) e o número de queda, em cinco classes: melhorador, pão, doméstico, básico e outros usos. O trigo, para ser enquadrado na classe melhorador, deve atender os valores mínimos estabelecidos quanto à força de glúten, à estabilidade e ao número de queda de 300 $\mathrm{W}, 14$ min e $250 \mathrm{~s}$, respectivamente, enquanto, para ser enquadrado nas demais classes, deve atender aos valores mínimos quanto à força de glúten ou à estabilidade e ao número de queda estabelecidos para as demais classes (Brasil, 2010).

Alguns melhoristas utilizaram a média dos valores de força de glúten de amostras de grãos de ensaios de competição de genótipos, para o enquadramento das cultivares nas classes comerciais (Scheeren et al., 2007; Marchioro et al., 2009; Silva et al., 2010). No entanto, em razão da influência de vários fatores, como manejo e fertilidade do solo (Pinnow et al., 2013), disponibilidade de água (Boschini et al., 2011), variáveis meteorológicas (Miloca et al., 2007) e condições de armazenagem (Gutkoski et al., 2008; Freo et al., 2011), os valores de força de glúten têm apresentado variação de magnitude, o que dificulta o uso da média como critério de classificação.

O problema torna-se evidente, quando há controvérsias entre o enquadramento das cultivares nas classes comerciais pelos obtentores (Reunião..., 2014) e os resultados obtidos pelos agricultores e moageiros (Brum \& Müller, 2008; Costa et al., 2008). Como principal causa do problema, suspeita-se de que o número de amostras utilizado pelos obtentores seja insuficiente e incompatível com a magnitude de variação existente, para o enquadramento das cultivares de trigo em classe comercial (Silva et al., 2010; Reunião..., 2014; Caierão et al., 2015). Uma das alternativas para sanar este problema poderia ser o redimensionamento do número de amostras baseado na média da força de glúten.

$\mathrm{O}$ objetivo deste trabalho foi estimar o número ideal de amostras, para a classificação comercial de cultivares de trigo quanto à média de força de glúten, no Rio Grande do Sul e Paraná, principais estados produtores de trigo do Brasil.

\section{Material e Métodos}

Para a estimativa do número ideal de amostras para a classificação comercial do trigo, com base na média de força de glúten, utilizaram-se os resultados das análises de alveografia realizadas pelo Laboratório de Qualidade de Grãos da Embrapa Trigo, referentes às cultivares 'BRS 208', 'BRS Guamirim' e 'Ônix'. Os critérios considerados na escolha das cultivares foram o número de amostras analisadas e a importância de cultivo. Procuraram-se cultivares com o maior número de análises disponíveis e com importância de cultivo atual ou recente (últimos dez anos), no Rio Grande do Sul e Paraná (Brasil, 2008), principais estados produtores do Brasil.

Utilizaram-se somente os resultados das análises de alveografia de amostras de grãos originadas de ensaios de competição de genótipos (ensaios preliminares, em rede, de valor de cultivo e uso - VCU - e de cultivares), tendo-se evitado os resultados provenientes de ensaios de manejo (adubação, espaçamento, densidade de semeadura, agroquímicos, entre outros), e de tratamentos não usuais em relação às condições de cultivo comercial. Os ensaios de competição de genótipos foram delineados em blocos ao acaso, com três ou quatro repetições, em que a unidade experimental constituiu-se de cinco fileiras de $5 \mathrm{~m}$ (ensaios em rede, de VCU e de cultivares) ou de $3 \mathrm{~m}$ de comprimento (ensaios preliminares), com espaço de $0,2 \mathrm{~m}$ entre si, com aproximadamente 330 plantas por metro quadrado. Cada amostra submetida à 
análise de alveografia foi obtida a partir da mistura e homogeneização dos grãos, colhidos nas três ou quatro repetições de cada genótipo, por ensaio.

Analisaram-se 60 e 220 amostras da cultivar 'BRS 208', dos estados do Rio Grande do Sul (em oito anos de experimentação) e do Paraná (em onze anos), respectivamente; da cultivar 'BRS Guamirim', 93 e 30 amostras do Rio Grande do Sul (dez anos) e do Paraná (oito anos), respectivamente; e da cultivar 'Ônix', 58 e 27 amostras, do Rio Grande do Sul (sete anos) e do Paraná (cinco anos), respectivamente.

Calcularam-se os seguintes parâmetros: os valores mínimo, máximo e médio de força de glúten (W, expresso em $10^{-4} \mathrm{~J}$ ); o desvio-padrão amostral (s'); o coeficiente de variação $(\mathrm{CV})$ das amostras; o intervalo de confiança para a média, a $95 \%$; e as estimativas dos números ideais de amostras (n), para as semiamplitudes do intervalo de confiança (margens de erro para mais ou para menos) de 30, 20 e 10 unidades de $\mathrm{W}(\mathrm{d}=30$; $\mathrm{d}=20$; e $\mathrm{d}=10$ ), das cultivares de trigo 'BRS 208', 'BRS Guamirim' e 'Ônix', por estado e por região homogênea de adaptação de cultivares de trigo, no Rio Grande do Sul e no Paraná. As regiões homogêneas de adaptação, especificadas no Zoneamento Agrícola de Risco Climático (Brasil, 2008), correspondem às seguintes regiões para a realização de ensaios deVCU: região 1, fria, úmida, alta - Rio Grande do Sul, Santa Catarina e Paraná; região 2, moderadamente quente, úmida e baixa - Rio Grande do Sul, Santa Catarina e Paraná; região 3, quente, moderadamente seca e baixa - Paraná, São Paulo e Mato Grosso do Sul (Figura 1).

O número ideal de amostras foi estimado com base nas propriedades da distribuição amostral da média, ou distribuição t de Student (Cochran, 1977), conforme a

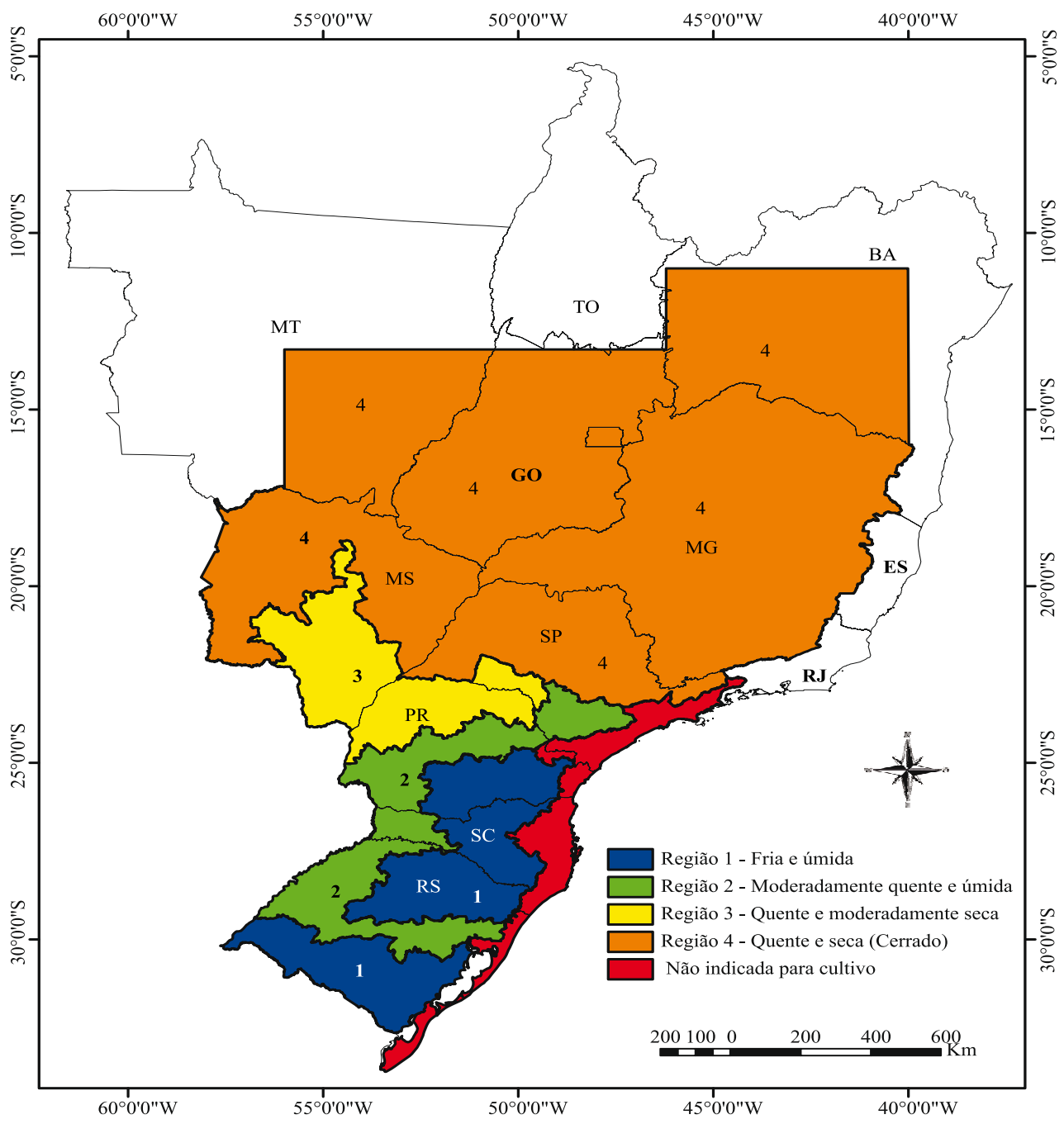

Figura 1. Regiões homogêneas de adaptação de cultivares de trigo (Brasil, 2008). 
equação: $\mathrm{n}=\left[\left(\mathrm{t}_{\alpha\left(\mathrm{n}^{\prime}-1\right)} \mathrm{s}^{\prime}\right) / \mathrm{d}\right]^{2}$, em que: $\mathrm{n}$ é o número ideal de amostras; n' é o número de amostras analisadas; s' é o desvio-padrão amostral; $\mathrm{t}_{\alpha\left(\mathrm{n}^{\prime}-1\right)}$ é a estatística $\mathrm{t}$ com $\alpha$ a $5 \%$ de probabilidade, e graus de liberdade $(\mathrm{GL})=$ n' - 1; e d, é a semiamplitude do intervalo de confiança, em unidades de força de glúten $\mathrm{W}$ expresso em $10^{-4} \mathrm{~J}$.

\section{Resultados e Discussão}

O valor mínimo de força de glúten da cultivar 'BRS 208 ' foi observado na região de adaptação 1 do Rio Grande do Sul (109 W), e o valor máximo, na região de adaptação 3 do Paraná (492 W) (Tabela 1). A média da força de glúten foi $237 \mathrm{~W}$ no Rio Grande do Sul e 296 W no Paraná. Os resultados de média e amplitude de variação da força de glúten foram semelhantes aos divulgados nas informações técnicas sobre a cultivar 'BRS 208' (Reunião..., 2014) e de acordo com os obtidos por Schmidt et al. (2009). Os números ideais de amostras quanto à média de força de glúten da cultivar 'BRS 208', estimados no Rio Grande do Sul, foram 22, 49 e 197, para as margens de erro (semiamplitudes do intervalo de confiança) de 30, 20 e $10 \mathrm{~W}$, respectivamente (Tabela 1). Para estes mesmos critérios, no Paraná, os números ideais foram estimados

Tabela 1. Número de amostras total, número de anos de amostragem, valor mínimo, máximo e médio de força de glúten (W), desvio-padrão amostral (s'), coeficiente de variação (CV) e número ideal de amostras (n), para as semiamplitudes do intervalo de confiança (d) iguais a 10 , 20 ou 30 unidades de W, da cultivar de trigo 'BRS 208', por região homogênea de adaptação $(\mathrm{RHA})^{(1)}$, nos Estados do Rio Grande do Sul e do Paraná.

\begin{tabular}{|c|c|c|c|c|c|c|c|}
\hline \multirow[t]{2}{*}{ Parâmetros } & \multicolumn{2}{|c|}{ RHA } & \multirow{2}{*}{$\begin{array}{c}\text { Estado } \\
\text { RS }\end{array}$} & \multicolumn{3}{|c|}{ RHA } & \multirow{2}{*}{$\begin{array}{c}\text { Estado } \\
\text { PR }\end{array}$} \\
\hline & $1 \mathrm{RS}$ & 2 RS & & $1 \mathrm{PR}$ & $2 \mathrm{PR}$ & $3 \mathrm{PR}$ & \\
\hline Número de amostras & 33 & 27 & 60 & 39 & 64 & 117 & 220 \\
\hline Número de anos & 8 & 5 & 8 & 11 & 11 & 11 & 11 \\
\hline W mínimo $\left(10^{-4} \mathrm{~J}\right)$ & 109 & 139 & 109 & 138 & 188 & 144 & 138 \\
\hline $\mathrm{W}$ máximo $\left(10^{-4} \mathrm{~J}\right)$ & 376 & 478 & 478 & 423 & 469 & 492 & 492 \\
\hline $\mathrm{W}$ média $\left(10^{-4} \mathrm{~J}\right)$ & 213 & 267 & 237 & 278 & 305 & 297 & 296 \\
\hline s' & 56,3 & 74,6 & 70,1 & 65,8 & 59,2 & 64,9 & 63,9 \\
\hline CV (\%) & 26,4 & 27,9 & 29,5 & 23,7 & 19,4 & 21,8 & 21,6 \\
\hline $\mathrm{n}(\mathrm{d}=10)$ & 132 & 236 & 197 & 178 & 140 & 166 & 157 \\
\hline $\mathrm{n}(\mathrm{d}=20)$ & 33 & 59 & 49 & 44 & 35 & 41 & 39 \\
\hline $\mathrm{n}(\mathrm{d}=30)$ & 15 & 26 & 22 & 20 & 16 & 18 & 17 \\
\hline
\end{tabular}

(1)Região homogênea de adaptação de cultivares de trigo no Rio Grande do Sul e no Paraná (Brasil, 2008). em 17, 39 e 157 amostras, respectivamente. O número ideal aumentou consideravelmente com a redução da margem de erro de 30 para 10 unidades de força de glúten e foi menor no Estado do Paraná do que no Rio Grande do Sul.

A precipitação pluvial, a umidade relativa do ar e a temperatura são variáveis meteorológicas que afetam a força de glúten do trigo (Guarienti et al., 2004; Miloca et al., 2007). No Rio Grande do Sul, ocorrem condições climáticas mais desfavoráveis, que proporcionam maior frequência de frustrações de safras e maior oscilação da qualidade do trigo (Brum \& Müller, 2008), o que pode justificar a necessidade do maior número de amostras. A constatação de maior variação da força de glúten, no Rio Grande do Sul, é sustentada pelos valores mais elevados de coeficiente de variação observados nesse Estado.

A força de glúten observada na 'BRS Guamirim' variou de $106 \mathrm{~W}$, na região de adaptação 1 do Rio Grande do Sul, a $464 \mathrm{~W}$, na região de adaptação 2 do Paraná (Tabela 2). A média da força de glúten foi de 239 W no Rio Grande do Sul e 287 W no Paraná. Scheeren et al. (2007) relataram média de força de glúten de $249 \mathrm{~W}$, com variação de $114 \mathrm{~W}$ a $375 \mathrm{~W}$, da cultivar 'BRS Guamirim', corroborada pelos resultados obtidos no presente trabalho. No Rio Grande do Sul,

Tabela 2. Número de amostras total, número de anos de amostragem, valor mínimo, máximo e médio de força de glúten (W), desvio-padrão amostral (s'), coeficiente de variação (CV) e número ideal de amostras (n), para as semiamplitudes do intervalo de confiança (d) iguais a 10, 20 ou 30 unidades de W, da cultivar de trigo 'BRS Guamirim', por região homogênea de adaptação $(\mathrm{RHA})^{(1)}$, nos Estados do Rio Grande do Sul e do Paraná.

\begin{tabular}{|c|c|c|c|c|c|c|c|}
\hline \multirow[t]{2}{*}{ Parâmetros } & \multicolumn{2}{|c|}{ RHA } & \multirow{2}{*}{$\begin{array}{c}\text { Estado } \\
\text { RS }\end{array}$} & \multicolumn{3}{|c|}{ RHA } & \multirow{2}{*}{$\begin{array}{c}\text { Estado } \\
\text { PR }\end{array}$} \\
\hline & $1 \mathrm{RS}$ & $2 \mathrm{RS}$ & & $1 \mathrm{PR}$ & $2 \mathrm{PR}$ & 3 PR & \\
\hline Número de amostras & 65 & 28 & 93 & 6 & 9 & 15 & 30 \\
\hline Número de anos & 10 & 8 & 10 & 5 & 5 & 4 & 8 \\
\hline W mínimo $\left(10^{-4} \mathrm{~J}\right)$ & 106 & 117 & 106 & 223 & 253 & 155 & 155 \\
\hline $\mathrm{W}$ máximo $\left(10^{-4} \mathrm{~J}\right)$ & 375 & 372 & 375 & 308 & 464 & 347 & 464 \\
\hline $\mathrm{W}$ média $\left(10^{-4} \mathrm{~J}\right)$ & 235 & 249 & 239 & 278 & 346 & 256 & 287 \\
\hline s' & 68,9 & 64,4 & 67,5 & 30,8 & 62,4 & 57,5 & 66,5 \\
\hline $\mathrm{CV}(\%)$ & 29,3 & 25,9 & 28,2 & 11,1 & 18,1 & 22,5 & 23,2 \\
\hline$\overline{n(d=10)}$ & 190 & 175 & 181 & 63 & 207 & 152 & 185 \\
\hline $\mathrm{n}(\mathrm{d}=20)$ & 47 & 44 & 45 & 16 & 52 & 38 & 46 \\
\hline $\mathrm{n}(\mathrm{d}=30)$ & 21 & 19 & 20 & 7 & 23 & 17 & 21 \\
\hline
\end{tabular}

(1)Região homogênea de adaptação de cultivares de trigo no Rio Grande do Sul e no Paraná (Brasil, 2008). 
os números ideais de amostras, relativos à média de força de glúten da cultivar 'BRS Guamirim', foram estimados em 20, 45 e 181 amostras, para as margens de erro de 30, 20 e 10 unidades de W, respectivamente. No Paraná, para estes mesmos critérios, os números ideais estimados foram muito semelhantes - 21, 46 e 185 -, respectivamente. Neste caso, a maior variação da força de glúten, observada no Rio Grande do Sul (maior coeficiente de variação), não resultou em estimativa mais elevada do número ideal de amostras. Isto ocorreu porque o número de amostras analisadas no Paraná foi consideravelmente menor, o que resultou em menor grau de liberdade e, consequentemente, maior valor da estatística $t_{\alpha\left(n^{\prime}-1\right)}$, positivamente relacionada à estimativa do número ideal (Cochran, 1977).

A cultivar 'BRS Guamirim' caracteriza-se por apresentar ampla adaptação (Franceschi et al., 2010). Ao comparar a estimativa do número ideal de amostras, para classificação comercial de 'BRS Guamirim', com o número de amostras utilizado por Marchioro et al. (2009), para a classificação de 'CD 117' (também com ampla adaptação), verifica-se que os números ideais estimados para 'BRS Guamirim' (20 amostras, no RS, e 21 no PR, para a margem de erro de $30 \mathrm{~W}$ ) são maiores do que o número utilizado para a classificação de 'CD 117' (13 amostras), com a particularidade de que Marchioro et al. (2009) utilizaram 13 amostras, para a classificação de 'CD 117', em oito estados e no Distrito Federal, ao passo que a estimativa do número ideal para 'BRS Guamirim' foi de 41 amostras $(20+21)$ para a classificação em somente dois estados (RS e PR).

O valor mínimo de força de glúten da cultivar 'Ônix' foi observado na região de adaptação 1 do Paraná $(128 \mathrm{~W})$, e o valor máximo $(486 \mathrm{~W})$, na região de adaptação 3 desse mesmo Estado (Tabela 3). A média da força de glúten foi de $244 \mathrm{~W}$ no Rio Grande do Sul e 307 W no Paraná. Schmidt et al. (2009) relataram média de força de glúten da cultivar 'Ônix' igual a 243 W no Rio Grande do Sul. Contudo, a amplitude de variação da força de glúten observada no presente trabalho foi maior do que a divulgada nas informações técnicas sobre a cultivar 'Ônix' (Reunião..., 2014). Esta diferença pode ser explicada como decorrência do maior número de amostras e anos de avaliação, considerados no presente trabalho, que representam maior diversidade de ambientes, condições climáticas e práticas de manejo que influenciam a força de glúten (Miloca et al., 2007; Boschini et al., 2011;
Pinnow et al., 2013). Os números ideais de amostras estimados no Rio Grande do Sul, relativos à média de força de glúten da cultivar 'Ônix', foram 13, 30 e 121 amostras, para as margens de erro de 30,20 e $10 \mathrm{~W}$, respectivamente e, no Paraná, os números ideais foram estimados em 21, 47 e 188 amostras, respectivamente. Para 'Ônix', de forma similar à 'BRS Guamirim', o menor número de amostras analisadas no Estado do Paraná resultou em maior estimativa do número ideal de amostras nesse Estado. Todavia, no Rio Grande do Sul, 'Ônix' apresentou a menor estimativa do número ideal (13 amostras), por estado, entre as três cultivares estudadas, para a margem de erro de $30 \mathrm{~W}$. Contudo, o número ideal de 13 amostras por estado ainda é maior do que o número utilizado para a classificação de novas cultivares de trigo (Marchioro et al., 2009; Franco et al., 2015).

A média de força de glúten foi maior no Estado do Paraná do que no Estado do Rio Grande do Sul, para as três cultivares estudadas (Tabelas 1, 2 e 3 ). Tanto no Rio Grande do Sul quanto no Paraná, a média de força de glúten foi sempre maior na região de adaptação 2 do que na região de adaptação 1. Estas diferenças, provavelmente, decorreram da temperatura, umidade relativa do ar e precipitação pluvial, que caracterizam a região de adaptação 2 (Brasil, 2008) e o Estado do

Tabela 3. Número de amostras total, número de anos de amostragem, valor mínimo, máximo e médio de força de glúten (W), desvio-padrão amostral (s'), coeficiente de variação (CV) e número ideal de amostras (n), para as semiamplitudes do intervalo de confiança (d) iguais a 10, 20 ou 30 unidades de W, da cultivar de trigo 'Ônix', por região homogênea de adaptação (RHA) ${ }^{(1)}$, nos Estados do Rio Grande do Sul e do Paraná.

\begin{tabular}{|c|c|c|c|c|c|c|c|}
\hline \multirow[t]{2}{*}{ Parâmetros } & \multicolumn{2}{|c|}{ RHA } & \multirow{2}{*}{$\begin{array}{c}\text { Estado } \\
\text { RS }\end{array}$} & \multicolumn{3}{|c|}{ RHA } & \multirow{2}{*}{$\begin{array}{c}\text { Estado } \\
\text { PR }\end{array}$} \\
\hline & $1 \mathrm{RS}$ & $2 \mathrm{RS}$ & & $1 \mathrm{PR}$ & $2 \mathrm{PR}$ & $3 \mathrm{PR}$ & \\
\hline de amostras & 29 & 29 & 58 & 6 & 16 & 5 & 27 \\
\hline Número de anos & 6 & 6 & 7 & 4 & 5 & 2 & 5 \\
\hline$\overline{\mathrm{W} \text { mínimo }\left(10^{-4} \mathrm{~J}\right)}$ & 136 & 179 & 136 & 128 & 250 & 222 & 128 \\
\hline no $\left(10^{-4} \mathrm{~J}\right)$ & 370 & 354 & 370 & 318 & 423 & 486 & 486 \\
\hline $\mathrm{W}$ média $\left(10^{-4} \mathrm{~J}\right)$ & 226 & 262 & 244 & 265 & 315 & 333 & 307 \\
\hline s' & 54,0 & 50,4 & 54,9 & 71,3 & 47,7 & 101,1 & 66,6 \\
\hline CV (\%) & 23,9 & 19,2 & 22,5 & 26,9 & 15,2 & 30,3 & 21,7 \\
\hline $\mathrm{n}(\mathrm{d}=10)$ & 122 & 107 & 121 & 336 & 103 & 788 & 188 \\
\hline $\mathrm{n}(\mathrm{d}=20)$ & 31 & 27 & 30 & 84 & 26 & 197 & 47 \\
\hline $\mathrm{n}(\mathrm{d}=30)$ & 14 & 12 & 13 & 37 & 11 & 88 & 21 \\
\hline
\end{tabular}

(1)Região homogênea de adaptação de cultivares de trigo no Rio Grande do Sul e no Paraná (Brasil, 2008). 
Paraná como tendo o clima mais favorável à obtenção de valores mais altos de força de glúten (Guarienti et al., 2004; Brum e Müller, 2008; Silva et al., 2010), independentemente da cultivar de trigo que se utilize (Scheeren et al., 2007; Reunião..., 2014; Caierão et al., 2015; Franco et al., 2015).

As estimativas do número ideal de amostras, para a classificação comercial das cultivares de trigo com base na média de força de glúten, por região de adaptação e por estado, variaram de 7 a 88, de 16 a 197, e de 63 a 788, respectivamente às margens de erro de 30, 20 e $10 \mathrm{~W}$ (Tabelas 1, 2 e 3). Ao comparar as estimativas do número ideal de amostras com o número utilizado, verifica-se que o número ideal é, geralmente, maior. Além disso, também se constata que a classificação comercial, em geral, não é feita por região de adaptação dentro de cada estado (Scheeren et al., 2007; Marchioro et al., 2009; Caierão et al., 2015; Franco et al., 2015), provavelmente em razão do número insuficiente de amostras. No ano 2013, das cinco novas cultivares de trigo lançadas comercialmente para cultivo no Estado do Rio Grande do Sul, três $(60 \%)$ e cinco cultivares $(100 \%)$ foram classificadas, com base em um número inferior ou igual a seis amostras de qualidade tecnológica (força de glúten), na regiões de adaptação 1 e 2 do Rio Grande do Sul, respectivamente (Reunião..., 2014).

O desvio-padrão da variável força de glúten, por região de adaptação do trigo nos principais estados produtores do Brasil, variou de $30,8 \mathrm{~W}$ a $101,1 \mathrm{~W}$ (Tabelas 1, 2 e 3), com média de $62 \mathrm{~W}$. O coeficiente de variação oscilou entre 11,1 e 30,3\%, com média de $22,8 \%$, em que a grande maioria dos valores ficou acima de $20 \%$, o que evidencia que a variável força de glúten tem alta variação nas principais regiões tritícolas do Brasil, especialmente no Rio Grande do Sul. Silva et al. (2014) constataram a influência da época de semeadura na força de glúten de sete cultivares de trigo, o que também salienta o efeito que o ambiente exerce sobre esta variável. Os autores observaram correlação negativa entre a força de glúten e o rendimento de grãos. Valores elevados de força de glúten podem estar associados ao maior acúmulo de proteínas (Pinnow et al., 2013), o que demanda maior consumo de carboidratos. O aumento do conteúdo de proteínas causa, portanto, redução do acúmulo de amido e, consequentemente, redução do rendimento de grãos (Schmidt et al., 2009; Silva et al., 2014).
Temperaturas mais elevadas, no período de enchimento de grãos de trigo, também estão associadas à redução do rendimento de grãos e ao aumento da força de glúten (Moldestad et al., 2011).

Nas três cultivares estudadas, pode-se verificar que há intervalos de confiança que transcendem os limites de força de glúten de uma classe comercial (Brasil, 2010) e abrangem, simultaneamente, duas ou três classes: doméstico e pão, pão e melhorador ou até mesmo doméstico, pão e melhorador (Figuras 2, 3 e 4). Portanto, a magnitude de variação da força de glúten, nas principais regiões tritícolas brasileiras, afeta a amplitude do intervalo de confiança para a média de modo que dificulta o enquadramento das cultivares nas classes comerciais.

A legislação brasileira não estabelece um número mínimo de amostras para a classificação comercial de cultivares de trigo (Brasil, 2008, 2010). Contudo, para a realização dos ensaios de VCU de trigo, para a inscrição de novas cultivares no Registro Nacional de Cultivares (RNC), o Ministério da Agricultura, Pecuária e Abastecimento (Mapa) estabeleceu - para as regiões homogêneas de adaptação 1,2 e 3 - o número mínimo de um local por região, em cada estado, durante três anos, ou dois locais por região, em cada estado, durante dois anos (Brasil, 2008). Para a obtenção de uma amostra de qualidade tecnológica por genótipo, por ensaio, as novas cultivares inscritas no RNC podem ter somente três ou quatro amostras de força de glúten, por região de adaptação, por estado.

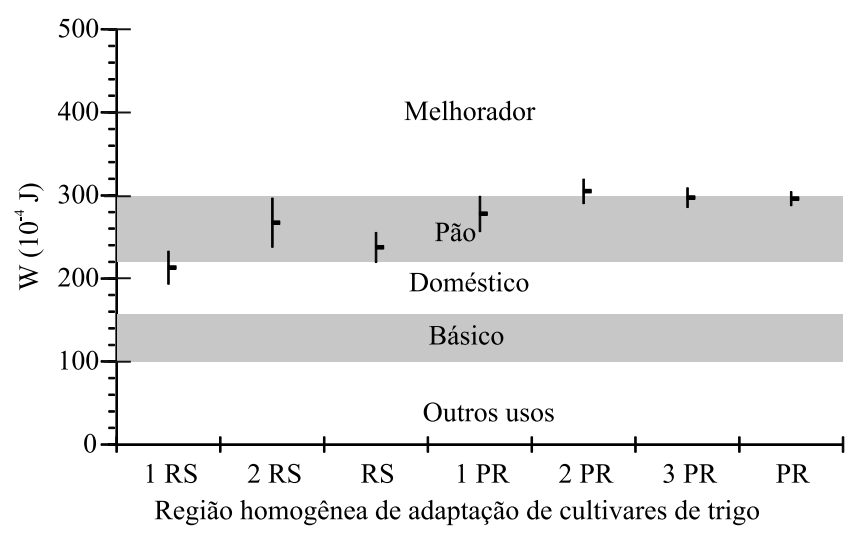

Figura 2. Intervalo de confiança a 95\%, para a média de força de glúten (W) da cultivar de trigo 'BRS 208', por região homogênea de adaptação, nos estados do Rio Grande do Sul e do Paraná (Brasil, 2008). 
Entretanto, este número de três ou quatro amostras está aquém do número ideal para a classificação comercial de cultivares de trigo quanto à média de força de glúten. No presente trabalho, o número ideal de amostras mínimo, estimado por estado, foi igual a 13, e o número ideal mínimo, estimado por região de adaptação e por estado, foi igual a sete, para a margem de erro de $30 \mathrm{~W}$. Para margem de erro menor, igual a 20 ou $10 \mathrm{~W}$, a estimativa do número ideal de amostras foi tão alta, que desafia os limites técnicos e econômicos viáveis de execução, em razão do custo das análises e experimentos.

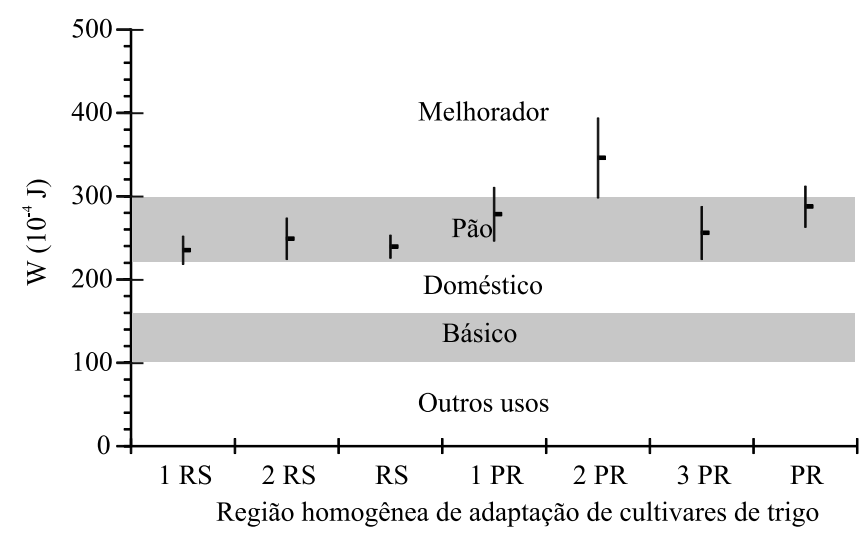

Figura 3. Intervalo de confiança a 95\%, para a média de força de glúten (W) da cultivar de trigo 'BRS Guamirim', por região homogênea de adaptação, nos estados do Rio Grande do Sul e do Paraná (Brasil, 2008).

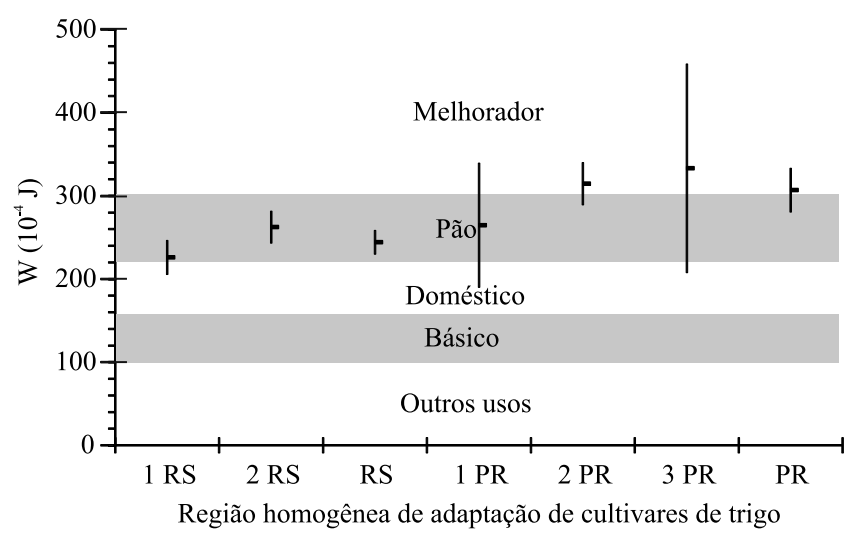

Figura 4. Intervalo de confiança a 95\%, para a média de força de glúten (W) da cultivar de trigo 'Ônix', por região homogênea de adaptação, nos estados do Rio Grande do Sul e do Paraná (Brasil, 2008).

\section{Conclusões}

1. Os números ideais de amostras, para a classificação comercial de cultivares de trigo quanto à média de força de glúten, no Rio Grande do Sul e Paraná, por estado, são de 13 a 22, 30 a 49, e 121 a 197 amostras, para as margens de erro de 30,20 e $10 \mathrm{~W}$, respectivamente.

2. O número ideal é no mínimo de sete amostras para a margem de erro de $30 \mathrm{~W}$-, para a classificação comercial de cultivares de trigo quanto à média de força de glúten, no Rio Grande do Sul e Paraná, por região homogênea de adaptação e por estado.

3. O número ideal de amostras para a classificação comercial do trigo, quanto à média de força de glúten, é maior do que o número de amostras utilizado pelos obtentores para a classificação de cultivares de trigo nos Estados do Rio Grande do Sul e Paraná.

\section{Referências}

ASSOCIAÇÃO BRASILEIRA DA INDÚSTRIA DO TRIGO. Estimativa aparente de participação da farinha no mercado de derivados 2005 a 2012. São Paulo: Abitrigo, 2012. 1p. Disponível em: <http://www.abitrigo.com.br/pdf/ PART-MERCADO-FARINHA-DERIVADOS-2012.pdf $>$. Acesso em: 23 jan. 2015.

BOSCHINI, A.P.M.; SILVA, C.L. da.; OLIVEIRA, C.A. da S.; OLIVEIRA JUNIOR, M. P. de; MIRANDA, M.Z. de; FAGIOLI, M. Aspectos quantitativos e qualitativos do grão de trigo influenciados por nitrogênio e lâminas de água. Revista Brasileira de Engenharia Agrícola e Ambiental, v.15, p.450-457, 2011. DOI: $10.1590 /$ S1415-43662011000500003.

BRASIL. Ministério da Agricultura, Pecuária e Abastecimento. Instrução Normativa n. ${ }^{\circ}$ 38, de 30 de novembro de 2010. [Estabelece o Regulamento Técnico do Trigo, definindo o seu padrão oficial de classificação, com os requisitos de identidade e qualidade, a amostragem, o modo de apresentação e a marcação ou rotulagem, nos aspectos referentes à classificação do produto]. Diário Oficial [da] República Federativa do Brasil, Brasília, 1 dez. 2010. Seção 1, p.2-4.

BRASIL. Ministério da Agricultura, Pecuária e Abastecimento. Instrução Normativa n. ${ }^{\circ}$ 58, de 19 de novembro de 2008. [Define regiões para a realização de ensaios de Valor de Cultivo e Uso de trigo, estabelece o número mínimo de locais por região para a realização de ensaios e oficializa a relação dos municípios que compõem as regiões]. Diário Oficial [da] República Federativa do Brasil, Brasília, 25 nov. 2008. Seção 1, p.3.

BRUM, A.L.; MÜLLER, P.K. A realidade da cadeia do trigo no Brasil: o elo produtores/cooperativas. Revista de Economia e Sociologia Rural, v.46, p.145-169, 2008. DOI: 10.1590/ S0103-20032008000100007. 
CAIERÃO, E.; SILVA, M.S. e; SCHEEREN, P.L.; CASTRO, R.L. de; EICHELBERGER, L.; NASCIMENTO JUNIOR, A. do; GUARIENTI, E.M.; MIRANDA, M.Z. de; PIRES, J.L.F.; MACIEL, J.L.N.; CHAVES, M.S.; SANTANA, F.M.; COSTAMILAN, L.; LIMA, M.I.P.M.; LAU, D.; PEREIRA, P.R.V. da S.; SILVA JÚNIOR, J.P. da; WIETHÖLTER, S.; CUNHA, G.R. da. Resultados agronômicos e qualitativos da nova cultivar de trigo 'BRS Marcante'. Ciência Rural, v.45, p.644-646, 2015. DOI: 10.1590/0103-8478cr20140838.

COCHRAN, W.G. Sampling techniques. $3^{\text {rd }}$ ed. New York: J. Wiley \& Sons, 1977. 428p.

COSTA, M. das G. da; SOUZA, E.L. de; STAMFORD, T.L.M.; ANDRADE, S.A.C. Qualidade tecnológica de grãos e farinhas de trigo nacionais e importados. Ciência e Tecnologia de Alimentos, v.28, p.220-225, 2008. DOI: 10.1590/ S0101-20612008000100031.

FRANCESCHI, L. de; BENIN, G.; MARCHIORO, V.S.; MARTIN, T.N.; SILVA, R.R.; SILVA, C.L. da. Métodos para análise de adaptabilidade e estabilidade em cultivares de trigo no estado do Paraná. Bragantia, v.69, p.797-805, 2010. DOI: 10.1590/s0006-87052010000400004.

FRANCO, F. de A.; MARCHIORO, V.S.; SCHUSTER, I.; NORA, T.D.; POLO, M.; LIMA, F.J.A. de; EVANGELISTA, A.; SANTOS, D.A. dos. CD 1550 - bread wheat cultivar with high gluten strength for the cooler regions of Brazil. Crop Breeding and Applied Biotechnology, v.15, p.48-50, 2015. DOI: $10.1590 / 1984-70332015 \mathrm{v} 15 \mathrm{n} 1 \mathrm{c} 9$.

FREO, J.D.; MORAES, L.B.D. de; COLUSSI, R.; MOSSMANN, J.; ELIAS, M.C.; GUTKOSKI, L.C. Propriedades físicas e tecnológicas de farinha de trigo tratada com terra diatomácea. Ciência Rural, v.41, p.1076-1081, 2011. DOI: 10.1590/ S0103-84782011005000061.

GUARIENTI, E.M.; CIACCO, C.F.; CUNHA, G.R. da; DEL DUCA, L. de J.A.; CAMARGO, C.M. de O. Influência das temperaturas mínima e máxima em características de qualidade industrial e em rendimento de grãos de trigo. Ciência e Tecnologia de Alimentos, v.24, p.505-515, 2004. DOI: 10.1590/ S0101-20612004000400005.

GUTKOSKI, L.C.; DURIGON, A.; MAZZUTTI, S.; SILVA, A.C.T. da; ELIAS, M.C. Efeito do período de maturação de grãos nas propriedades físicas e reológicas de trigo. Ciência e Tecnologia de Alimentos, v.28, p.888-894, 2008. DOI: 10.1590/ S0101-20612008000400019.

GUTKOSKI, L.C.; KLEIN, B.; PAGNUSSATT, F.A.; PEDÓ, I. Características tecnológicas de genótipos de trigo (Triticum aestivum L.) cultivados no Cerrado. Ciência e Agrotecnologia, v.31, p.786-792, 2007. DOI: 10.1590/ S1413-70542007000300027.

MARCHIORO, V.S.; FRANCO, F. de A.; NORA, T.D.; OLIVEIRA, E.F. de; SCHUSTER, I.; VIEIRA, E.S.N.; EVANGELISTA, A. CD 117: nova cultivar de trigo de ampla adaptação. Pesquisa Agropecuária Brasileira, v.44, p.424-426, 2009. DOI: 10.1590/S0100-204X2009000400015.

MILOCA, S.A.; CHAVES NETO, A.; VOLPI, N.M.P.; CONEJO, P.D. Relação entre variáveis meteorológicas e a qualidade industrial do trigo. Ciência Rural, v.37, p.31-37, 2007. DOI: $10.1590 /$ S0103-84782007000100006.

MIS, A.; GRUNDAS, S.; DZIKI, D.; LASKOWSKI, J. Use of farinograph measurements for predicting extensograph traits of bread dough enriched with carob fibre and oat wholemeal. Journal of Food Engineering, v.108, p.1-12, 2012. DOI: 10.1016/j.jfoodeng.2011.08.007.

MÓDENES, A.N.; SILVA, A.M. da; TRIGUEROS, D.E.G. Avaliação das propriedades reológicas do trigo armazenado. Ciência e Tecnologia de Alimentos, v.29, p.508-512, 2009. DOI: $10.1590 / \mathrm{S} 0101-20612009000300008$.

MOLDESTAD, A.; FERGESTAD, E.M.; HOEL, B.; SKJELVÀG, A.O.; UHLEN, A.K. Effect of temperature variation during grain filling on wheat gluten resistance. Journal of Cereal Science, v.53, p.347-354, 2011. DOI: 10.1016/j.jcs.2011.02.005.

OLÁN, M. De la O.; RANGEL, E.E.; MIR, H.E.V.; GALÁN, J.D.M.; SÁNCHES, H.L.; VARELA, A.S.; BAUTISTA, R.J.P. Proteínas del gluten y reología de trigos harineros mexicanos influenciados por factores ambientales y genotípicos. Pesquisa Agropecuária Brasileira, v.45, p.989-996, 2010. DOI: 10.1590/S0100-204X2010000900008.

PINNOW, C.; BENIN, G.; VIOLA, R.; SILVA, C.L. da; GUTKOSKI, L.C.; CASSOL, L.C. Qualidade industrial do trigo em resposta à adubação verde e doses de nitrogênio. Bragantia, v.72, p.20-28, 2013. DOI: 10.1590/ S0006-87052013005000019.

REUNIÃO DA COMISSÃO BRASILEIRA DE PESQUISA DE TRIGO E TRITICALE, 7., 2013, Londrina. Informações técnicas para trigo e triticale: safra 2014. Londrina: Fundação Meridional, 2014. 235p.

SCHEEREN, P.L.; CAIERÃO, E.; SILVA, M.S. e; DEL DUCA, L. de J.A.; NASCIMENTO JUNIOR, A. do; LINHARES, A.; EICHELBERGER, L. BRS Guamirim: cultivar de trigo da classe pão, precoce e de baixa estatura. Pesquisa Agropecuária Brasileira, v.42, p. 293-296, 2007. DOI: $10.1590 / \mathrm{S} 0100-204 \mathrm{X} 2007000200020$.

SCHEUER, P. M.; FRANCISCO, A. de; MIRANDA, M.Z. de; OGLIARI, P.J.; TORRES, G.; LIMBERGER, V.; MONTENEGRO, F.M.; RUFFI, C.R.; BIONDI, S. Characterization of Brazilian wheat cultivars for specific technological applications. Ciência e Tecnologia de Alimentos, v.31, p.816-826, 2011. DOI: 10.1590/ S0101-20612011000300041.

SCHMIDT, D.A.M.; CARVALHO, F.I.F. de; OLIVEIRA, A.C. de; SILVA, J.A.G. de; BERTAN, I.; VALÉRIO, I.P.; HARTWIG, I.; SILVEIRA, G. da; GUTKOSKI, L.C. Variabilidade genética em trigos brasileiros a partir de caracteres da qualidade industrial e produção de grãos. Bragantia, v.68, p.43-52, 2009. DOI: 10.1590/S0006-87052009000100006.

SILVA, M.S. e; CAIERÃO, E.; SCHEEREN, P.L.; NASCIMENTO JUNIOR, A. do; MIRANDA, M.Z de. BRS 327: a new bread wheat cultivar. Crop Breeding and Applied Biotechnology, v.10, p.370-373, 2010. DOI: 10.12702/1984-7033.v10n04c01. 
SILVA, R.R.; BENIN, G.; ALMEIDA, J.L. de; FONSECA, I.C. de B.; ZUCARELI, C. Grain yield and baking quality of wheat under different sowing dates. Acta Scientiarum. Agronomy, v.36, p.201-210, 2014. DOI: 10.4025/actasciagron. v36i2.16180.

SMANHOTTO, A.; NÓBREGA, L.H.P.; OPAZO, M.A.U.; PRIOR, M. Características físicas e fisiológicas na qualidade industrial de cultivares e linhagens de trigo e triticale. Revista Brasileira de Engenharia Agrícola e Ambiental, v.10, p.867-872, 2006. DOI: 10.1590/S1415-43662006000400013.

WAN, Y.; SHEWRY, P.R.; HAWKESFORD, M.J. A novel family of $\gamma$-gliadin genes are highly regulated by nitrogen supply in developing wheat grain. Journal of Experimental Botany, v.64, p.161-168, 2013. DOI: 10.1093/jxb/ers318.

Recebido em 4 de março de 2016 e aprovado em 17 de maio de 2016 